\title{
Inconsistency in the items included in tools used in general health research and physical therapy to evaluate the methodological quality of randomized controlled trials: a descriptive analysis
}

Susan Armijo-Olivo ${ }^{1,2^{*}}$, Jorge Fuentes ${ }^{2,3}$, Maria Ospina ${ }^{4}$, Humam Saltaji ${ }^{5}$ and Lisa Hartling ${ }^{6}$

\begin{abstract}
Background: Assessing the risk of bias of randomized controlled trials (RCTs) is crucial to understand how biases affect treatment effect estimates. A number of tools have been developed to evaluate risk of bias of RCTs; however, it is unknown how these tools compare to each other in the items included. The main objective of this study was to describe which individual items are included in RCT quality tools used in general health and physical therapy (PT) research, and how these items compare to those of the Cochrane Risk of Bias (RoB) tool.
\end{abstract}

Methods: We used comprehensive literature searches and a systematic approach to identify tools that evaluated the methodological quality or risk of bias of RCTs in general health and PT research. We extracted individual items from all quality tools. We calculated the frequency of quality items used across tools and compared them to those in the RoB tool. Comparisons were made between general health and PT quality tools using Chi-squared tests.

Results: In addition to the RoB tool, 26 quality tools were identified, with 19 being used in general health and seven in PT research. The total number of quality items included in general health research tools was 130, compared with 48 items across PT tools and seven items in the RoB tool. The most frequently included items in general health research tools (14/19, 74\%) were inclusion and exclusion criteria, and appropriate statistical analysis. In contrast, the most frequent items included in PT tools $(86 \%, 6 / 7)$ were: baseline comparability, blinding of investigator/assessor, and use of intention-to-treat analysis. Key items of the RoB tool (sequence generation and allocation concealment) were included in 71\% (5/7) of PT tools, and 63\% (12/19) and 37\% (7/19) of general health research tools, respectively.

Conclusions: There is extensive item variation across tools that evaluate the risk of bias of RCTs in health research. Results call for an in-depth analysis of items that should be used to assess risk of bias of RCTs. Further empirical evidence on the use of individual items and the psychometric properties of risk of bias tools is needed.

Keywords: Bias, Methodological quality, Quality assessment, Critical appraisal, Risk of bias, Quality of reporting

\footnotetext{
* Correspondence: susanarmijo@gmail.com

${ }^{1}$ Postdoctoral Fellow, CLEAR (Connecting Leadership and Research)

Outcomes Research Program, University of Alberta, 5-115A Edmonton Clinic

Health Academy (ECHA), 11405 - 87 Avenue, Edmonton, Alberta T6G 1C9

Canada

${ }^{2}$ Faculty of Rehabilitation Medicine, Department of Physical Therapy,

University of Alberta, 3-48 Corbett Hall, Edmonton T6G 2G4, Canada

Full list of author information is available at the end of the article
} 


\section{Background}

Randomized controlled trials (RCTs), and systematic reviews (SRs) and meta-analyses of these trials, are considered the gold standard to evaluate the effectiveness of health care interventions. Results of these studies are crucial for informing the implementation of the best treatments to improve patient outcomes and the efficiency of the health care system. Evaluating the methodological quality of trials is an essential component of SRs as only the best available evidence should inform clinical and policy decisions. An accurate assessment of study quality is key for the synthesis and interpretation of results across studies to effectively guide health care [1].

The term "methodological quality" has evolved since its inception and involves the evaluation of the internal validity as well as the external validity of a given study [2,3]. Recently, The Cochrane Collaboration has lead a shift in the approach to quality assessment, in which the concept of trial quality is linked to the internal validity of the study, namely risk of bias [4]. However, there is still inconsistency among researchers on how study quality is defined, and several terms have been used interchangeably in the literature (i.e. quality assessment, methodological quality, risk of bias, critical appraisal, trial quality).

While the impact of trial bias on evidence synthesis has been largely recognized, the approaches to quality assessment have been inconsistent and controversial [5]. A wide variety of tools have been developed to evaluate RCT quality in different health areas.[5,6]; many of them have not been developed using scientifically rigorous methods nor have they been validated [5]. In addition, there is no agreement on the optimal tool to accurately assess trial quality. The use of different tools for evaluating the quality of primary research in SRs can lead to discrepancies and skewed interpretations of SR results [7-9] and ultimately impact recommendations for clinical care.

In 2008, The Cochrane Collaboration [10] introduced the Risk of Bias (RoB) tool as a way to address shortcomings associated with existing tools and methods for quality assessment in SRs. Individual RoB items were selected based on a growing body of empirical evidence quantifying the association between certain characteristics related to the conduct of the trial and estimates of treatment effects [11-15]. For example, there is evidence that inadequate allocation concealment or lack of double-blinding are likely to overestimate treatment effects by $18 \%$ and $9 \%$, respectively $[12,14,15]$.

In order to guide a proper assessment of study quality or risk of bias to inform decision-making, it is important to identify which items have been included in different tools and whether these items truly evaluate the likelihood of bias, as defined by The Cochrane Collaboration $[10,16]$ and other criteria [17]. This would be an important contribution for evidence synthesis.

Most of the studies that have evaluated the use of tools for quality assessment of RCTs $[5,6,18,19]$ have not exhaustively assessed how these tools compare to each other in terms of their individual items and whether their use varies across different areas of health care research. For example, a recent study [19] examined the characteristics and methods of reviews assessing the quality of RCTs. While substantial variation in the use of quality tools across reviews was identified, the study did not describe in detail which items were most frequently included in the tools. The present study was designed to refine the analysis of existing tools by conducting a more comprehensive search (i.e., no language restrictions, larger number of databases), describing the psychometric properties of the tools used in general health research, and comparing the items included in these tools with the Cochrane RoB tool.

We conducted a previous systematic review that described which tools have been used to evaluate the methodological quality of RCTs in physical therapy (PT) research [5]. RCTs conducted in the area of PT have unique characteristics compared with pharmacological trials. Because of the nature of PT treatments (e.g., manual therapy, exercises), RCTs assessing PT interventions are often complex [20], and diverse aspects of their design (e.g., type and intensity of therapy, standardized or individually tailored approaches, therapists' skills and experience) are likely to affect study results. It is unknown whether the tools to assess the quality of RCTs in PT differ from those used in general health research in terms of the items and type of bias they aim to address. The present study was designed to expand and update the analysis of our previous review [5] on quality tools for evidence synthesis.

The main objective of the present study was to describe the frequency of individual items included in tools that assess RCT quality in general health and PT research, and how they compare to items included in the RoB tool [4]. Secondary objectives were to 1 ) determine the nature of items included in general health and PT quality tools (i.e., evaluation of "conduct" versus "reporting"); 2) report on the psychometric properties of quality tools that have been formally evaluated; 3 ) determine whether individual items in the tools relate to certain threats to validity or precision $[10,16,17]$ and 4 ) quantify the number of citations per tool, as a measure of usage since each tool's inception and after inception of the RoB tool. 


\section{Methods \\ Design: observational, descriptive study Search strategy}

An update of a previous SR [5] on quality assessment tools was carried out to identify scales and their items used in the assessment of RCT quality in health and PT research. The updated search strategy incorporated key words identified by Dechartres et al. [19], with searches conducted from January 1st, 2007 to June 10, 2013 in the following bibliographic databases: Medline, Embase, Cinahl, ISI Web of Science, EMB Reviews-Cochrane Central Register of Controlled Trials and Cochrane Library and Best Evidence, All EBM Reviews -CDSR, ACP journal Club, DARE, CCTR, Global health, and HealthSTAR. Key words used in the search were: tool, critical appraisal, critical appraisal review, appraisal of methodology, appraisal of research methodology, research design review, quality assessment, methodological quality tool, RoB (tool), randomized (randomised) controlled trial, and RCT. Additionally, we manually searched the bibliographies of potentially relevant papers. The search was not limited by language of publication. For a sample search strategy, see Additional file 1.

\section{Criteria for inclusion of studies in the review}

Studies were included if they described or used a newly developed tool to evaluate the methodological quality/ RoB of RCTs in any area of medical/health research and described any of its psychometric properties (i.e. validity, reliability, responsiveness). We excluded studies in which quality tools were developed for only one specific SR, studies that were not related to the development or psychometric testing of quality tools, and studies on generic tools that evaluated different types of research design (e.g., qualitative and quantitative studies). In addition, studies using modifications of existing tools were not considered for inclusion as they were likely not systematically developed. The RoB tool $[4,10]$ was known to be newly developed after our previous SR (2008), and was included prior to the updated search; however, we searched for manuscripts reporting psychometric properties of the RoB tool.

\section{Data screening}

Two reviewers independently screened abstracts and titles obtained from the database searches. The full text of potentially relevant articles was retrieved for further assessment. Disagreements were resolved by consensus.

\section{Data extraction}

Data extraction was conducted in two phases. First, two researchers independently extracted information on content, construction, special features (e.g. area of development-clinical area-, number of items, selection of items for inclusion, time to complete, scoring instructions), and psychometric properties of the new tools. Information on face, content, construct, and concurrent validity, internal consistency, and reproducibility (intra and inter-rater reliability/agreement) was extracted. For this update, authors of original studies were not contacted to obtain additional information. The definitions of psychometric properties from Streiner and Norman [21-23] were used in the present study. Guidelines developed by Terwee et al. [24] were used to define quality of measurement properties. Briefly, quality of measurement included internal (internal consistency, relevance of items and representativeness of items of the scale-content validity) as well as external components of validity (the relationship with other tests in a manner that is consistent with theoretically derived hypothesesconstruct validity). Intra and inter-rater reliability (i.e. repeatability of measurements taken by the same tester at different times and repeatability of measurements taken by different testers, respectively) were also considered. Definitions of psychometric properties for this review are provided in Additional file 2.

Second, two researchers independently extracted information on individual items used in the tools and the frequency of items across tools. Tools were categorized as relevant to PT if the authors specifically stated that the scale was developed for PT research, it was developed by a PT group, or if, according to Scopus searches, the tool was used in at least $5 \mathrm{PT}$ reviews. Otherwise the tool was considered a general health research tool. One of the tools commonly used in both general health and PT research is the Jadad scale. This tool was included in both categories.

Items from the quality tools were grouped according to nine content categories that have been previously described [5]: 1) introduction, objectives, and design; 2) patient selection (inclusion and exclusion criteria, description of study participants); 3) assignment, randomization, and allocation concealment; 4) blinding; 5) interventions; 6) attrition, follow up and protocol deviations; 7) outcomes; 8) statistical analysis; and 9) miscellaneous.

\section{Classification of items}

Methodological quality (conduct) and quality of reporting are two concepts that overlap to some degree; however, they relate to different aspects of study quality. We defined methodological quality as "the confidence that the trial design, conduct, and analysis has minimized or avoided biases in its treatment comparisons" [6] (e.g., allocation concealment was appropriate). We defined quality of reporting as authors providing "information about the design, conduct and analysis of the trial," [6] (e.g., method for concealing allocation was reported). 
Two researchers independently classified individual items based on whether they evaluated "reporting" and/ or "conduct" of the trial.

Classifying quality items is a complex task due to unclear description of items in the tools, lack of general agreement in bias definitions [25], and the need for empirical evidence linking these items to bias. Two researchers independently classified each item according to whether they potentially addressed threats to validity (i.e., selection bias, detection bias, performance bias, attrition bias) or precision (Additional file 3). These categorizations have been used in other relevant sentinel work [17,26-28]. Items that dealt with several threats to validity were classified as addressing multiple biases [29]. Reviewers considered each item by asking "What type of threats to validity or precision are addressed by a given item?" or "What do authors intend to capture with a given quality assessment item?" Thus, items were classified into the threats to validity or precision that best represented the concepts being addressed. We performed this task in duplicate and based on the guidelines established. The same type of analysis has been conducted previously for prognosis research [28]. Disagreements in item classification were resolved by consensus.

\section{Tool citation}

Each quality tool was tracked in the Scopus database to determine the number of times that the tool was cited since its original paper/citation. The number of citations per tool was tracked from January 1, 2007 to July 4, 2013 to describe recent uses of the tool and to ascertain whether the use of the tool declined after introduction of the RoB tool. The RoB tool was originally described in Chapter 8 of the Cochrane Handbook [10]. Since books and book chapters are not indexed in electronic databases, it was more challenging to track citations for the RoB tool. We tracked RoB citations using Google Scholar and the journal publication by Higgins et al. [4], that reported on the RoB tool.

\section{Analysis}

Data were summarized descriptively as the frequency of each item across quality tools, and within general health and PT research. Comparisons of items from PT and general health research tools with the RoB tool were also conducted. Comparisons between the proportion of individual items used by PT tools and general health research tools were performed using Chi-squared or Fisher exact tests. The alpha level was set at $\alpha=0.05$. The level of agreement between reviewers for study selection and data extraction from quality tools was calculated using percentage agreement and the Kappa ( $\mathrm{k}$ ) statistic [30]. Analyses were performed using Stata
Statistical Software: Version 12, 2012 (College Station, TX: StataCorp LP).

\section{Results}

The updated electronic searches identified 32,627 citations. Manual searches identified four additional studies based on their titles and abstracts. After screening titles and abstracts, 154 articles were deemed potentially relevant. The application of the selection criteria resulted in 148 excluded studies. The main reasons for exclusion of studies were: 1) the study used a quality tool for which information on construction, development and/or psychometric properties was not available $(n=40) ; 2)$ the tool was already included in the original review $(n=39)$; 3) the study used a tool that was not specific for RCT quality assessment $(\mathrm{n}=23)$; 4 ) the study used a modified tool already included in the review $(n=20) ; 5)$ the study used an instrument that was not a quality tool $(\mathrm{n}=11)$; 6) the study used a tool developed for the purposes of a single review $(\mathrm{n}=8) ; 7)$ the study focused on animal research $(n=4) ; 8)$ the study did not focus on a particular tool $(n=2)$; and 9) information on the name of the tool was not provided $(n=1)$. A list of excluded studies and reasons for exclusion is available in Additional file 4. The level of agreement for study selection between reviewers was excellent (kappa $=0.96)$.

Six manuscripts [31-36] reporting on four newly developed tools met the eligibility criteria (Figure 1). These four new tools that evaluated the methodological quality/RoB of RCTs in health research in addition to the RoB tool [4,10] were: the Cochrane Collaboration Depression, Anxiety, And Neurosis (CCDAN) tool [34,35], the Randomized Controlled Trial Psychotherapy Quality Rating Scale (RCT-PQRS Tool) [32,33], 3) the Randomized Controlled Trial -Natural Products Tool (RCT-NP) [31], and the CLEAR NPT (a checklist to evaluate the report of nonpharmacological trials) [36]. New PTspecific tools were not identified. The five tools were added to the 21 tools identified in our previous review [2] (i.e. Jadad [37], Maastricht [38], Delphi [39], PeDro [40,41], Maastricht-Amsterdam [42], Van Tulder [43], Bizzini [44], Chalmers [45], Reisch [46], Andrew [47], Imperiale [48], Detsky [49], Cho and Bero [50], Balas [51], Sindhu [52], Downs and Black [53], Nguyen [54], Oxford Pain Validity Scale (OPVS) [55], Arrive [56], CONSORT [57], and Yates [58]). Therefore, this update includes 26 quality tools. Details on the characteristics and psychometric properties of the new quality tools are presented in Tables 1 and 2 .

Most of the new tools have been tested for face and content validity (Table 2 and Additional file 5). Evaluations of other types of validity, such as criterion validity, have been conducted only for the RCT-NP and the RoB tool; however, the criterion used was a non-gold 


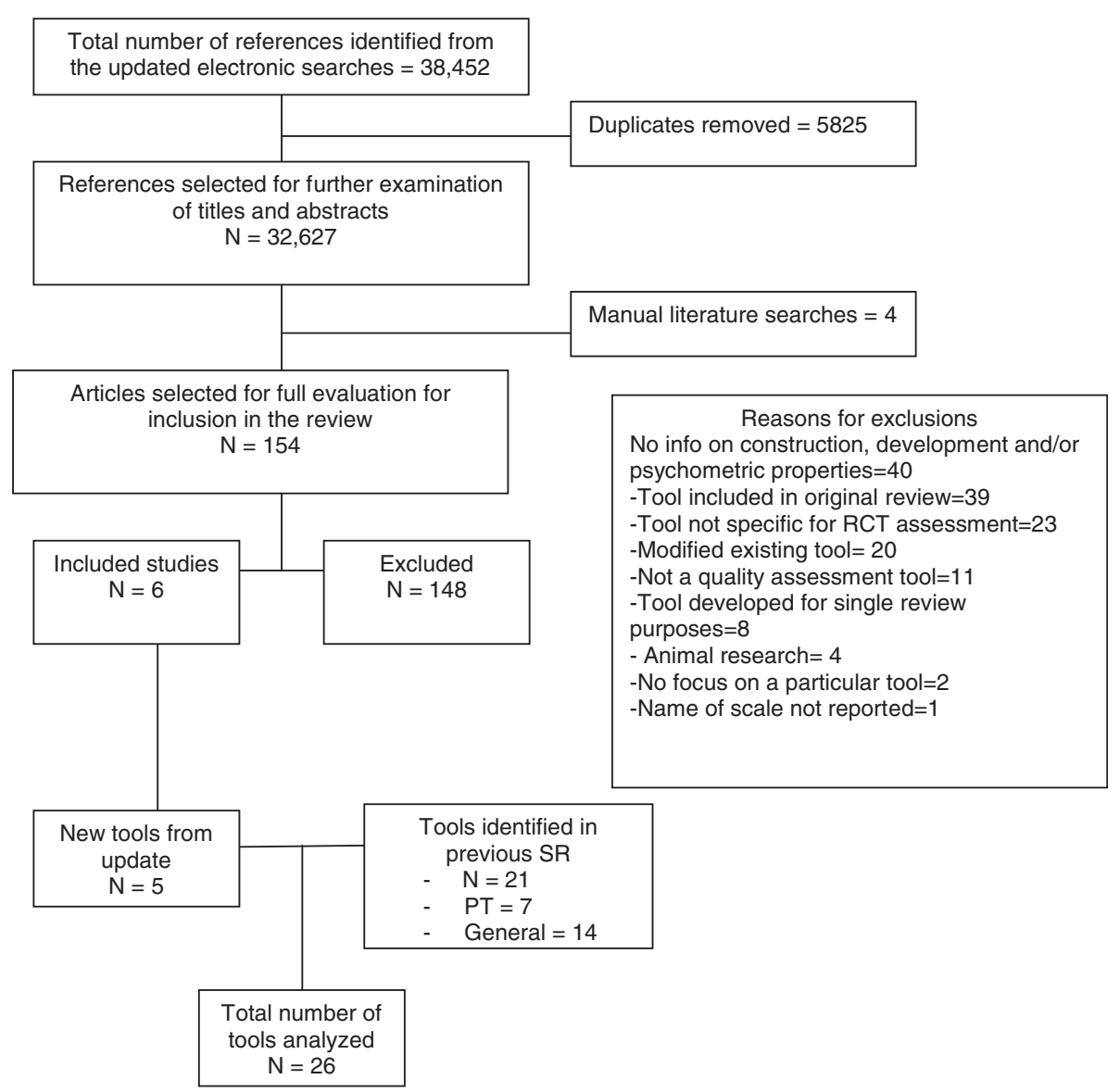

Figure 1 PRISMA flow diagram for identification of studies.

standard tool (since to date, there is no accepted gold standard to evaluate the risk of bias or quality of RCTs in health research). Tool reproducibility has been evaluated for the CCDAN tool, the RCT-PQRS, and the RoB tool. The inter-rater reliability of the RoB tool was fair $(\mathrm{k}=0.41$ 0.60) in contrast to the CCDAN and RCT-PQRS tools which showed good inter-rater reliability $(r=0.75-0.86$; intra class correlation coefficient $[\mathrm{ICC}]=0.76-0.79)$.

Items from all 26 tools were summarized according to their frequency of use. The level of agreement between reviewers for item categorization in both PT (kappa = $0.92)$ and general health research tools $(\mathrm{kappa}=0.98)$ was very good to excellent.

\section{Tools to measure methodological quality/risk of bias}

Of the 26 tools, 19 have been used in general health research and seven in PT research (including the Jadad scale, which is commonly used in both research areas). A total of 130 items have been used across general heath research tools compared with 48 items used in PT tools. The RoB tool has 6 domains with 7 items in total. Additional files 5 and 6 provide a detailed description of individual items contained in the tools. The numbers of quality items according to the nine content categories for general health versus PT tools were: introduction, objectives, and design: 8 versus 0 items; patient selection: 18 versus 4 items; assignment, randomization, and allocation concealment: 8 versus 5 items; blinding: 12 versus 10 items; interventions: 17 versus 8 items; attrition, follow up and protocol deviation: 10 versus 9 items; outcomes: 15 versus 7 items; statistical analysis: 31 versus 5 items, and miscellaneous: 11 versus 0 items.

\section{Frequency of items: General health research tools, physical therapy tools and RoB tool}

Items addressing inclusion and exclusion criteria and the appropriateness of statistical analysis were the most frequently used among the general health research tools (74\%, 14/19 tools). The second most commonly used items in general health research tools were description of withdrawals and drop outs, description and appropriateness of randomization process, blinding of investigators/assessors, and description of treatment protocol for both intervention and control groups (63\%, 12/19 tools).

In contrast, baseline comparability, blinding of investigator/assessor, and use of intention-to-treat analysis 


\begin{tabular}{|c|c|c|c|c|c|c|c|}
\hline Study (authors, year) & Area & Numbers of items & $\begin{array}{l}\text { How items were selected } \\
\text { for inclusion }\end{array}$ & Validity & Reliability & $\begin{array}{l}\text { Time to } \\
\text { complete }\end{array}$ & $\begin{array}{l}\text { Guidelines } \\
\text { for use } \\
\text { available }\end{array}$ \\
\hline \multicolumn{8}{|l|}{ NEW TOOLS (2007-2013) } \\
\hline \multirow{5}{*}{$\begin{array}{l}\text { COCHRANE COLLABORATION } \\
\text { DEPRESSION, ANXIETY, AND } \\
\text { NEUROSIS (CCDAN) [34,35] }\end{array}$} & \multirow{5}{*}{$\begin{array}{l}\text { Trials of } \\
\text { depression, } \\
\text { anxiety and } \\
\text { neurosis. } \\
\text { Psychological } \\
\text { and } \\
\text { Psychiatric } \\
\text { trials }\end{array}$} & \multirow[t]{5}{*}{23 items } & \multirow{3}{*}{$\begin{array}{l}\text { This tool was developed from } \\
\text { items included in other } \\
\text { health tools (especially } \\
\text { CONSORT statement), and } \\
\text { then a consensus from } \\
\text { experts was performed to } \\
\text { determine a pilot tool to be } \\
\text { tested. }\end{array}$} & $\begin{array}{l}\text { Face, content and construct } \\
\text { validity }\end{array}$ & \multirow{2}{*}{$\begin{array}{l}\text { Reliability evaluated through } \\
\text { correlation coefficient among } \\
3 \text { raters in total score was } \\
\text { high. It ranged from } r=0.75- \\
0.86 \text {. }\end{array}$} & \multirow{5}{*}{$\begin{array}{l}15-20 \\
\text { minutes }\end{array}$} & \multirow[t]{5}{*}{ No } \\
\hline & & & & \multirow[t]{4}{*}{$\begin{array}{l}\text { Scores from raters correlated } \\
\text { highly with year of } \\
\text { publication }(r=0.37-0.6)\end{array}$} & & & \\
\hline & & & & & $\begin{array}{l}\text { Reliability for individual items } \\
\text { was less strong }\end{array}$ & & \\
\hline & & & \multirow{2}{*}{$\begin{array}{l}\text { Further validation consisted } \\
\text { on determine reliability of } \\
\text { the tool as well as internal } \\
\text { consistency and its } \\
\text { correlation with overall score } \\
\text { and year of publication. }\end{array}$} & & $\begin{array}{l}\text { The mean kappa for all } 23 \\
\text { items ranged between } 0.51 \\
\text { to } 0.54 \text { among } 3 \text { raters }\end{array}$ & & \\
\hline & & & & & $\begin{array}{l}\text { Internal consistency } \\
\text { measured through Cronbach } \\
\text { alpha ranged between } 0.65 \\
\text { to } 0.78\end{array}$ & & \\
\hline \multirow[t]{5}{*}{$\begin{array}{l}\text { THE RANDOMIZED } \\
\text { CONTROLLED TRIAL } \\
\text { PSYCHOTHERAPY QUALITY } \\
\text { RATING SCALE (RCT-PQRS } \\
\text { TOOL) [32,33] }\end{array}$} & \multirow[t]{5}{*}{ Psychotherapy } & \multirow{5}{*}{$\begin{array}{l}25 \text { items organized in } 6 \\
\text { domains: Description of } \\
\text { subject ( } 4 \text { items), definition } \\
\text { and delivery of treatment ( } 5 \\
\text { items), outcome measures ( } 5 \\
\text { items), data analysis ( } 5 \text { items), } \\
\text { treatment assignment ( } 3 \\
\text { items), overall quality of } \\
\text { study ( } 3 \text { items) }\end{array}$} & \multirow{5}{*}{$\begin{array}{l}\text { Items were generated by an } \\
\text { informal expert consensus } \\
\text { (members of the American } \\
\text { Psychiatric Committee on } \\
\text { Research on Psychiatric } \\
\text { treatments, outside } \\
\text { consultants, who were senior } \\
\text { psychotherapy and/or } \\
\text { psychopharmacology clinical } \\
\text { researchers. }\end{array}$} & $\begin{array}{l}\text { The Cronbach a for all } 25 \\
\text { items as rated by the primary } \\
\text { rater was } 0.87 \text {. }\end{array}$ & $\begin{array}{l}\text { The ICC for interrater } \\
\text { reliability of item } 25 \text {, the } \\
\text { omnibus rating of the quality } \\
\text { of the study, was } 0.79 \text {. }\end{array}$ & \multirow[t]{5}{*}{$\begin{array}{l}\text { 10-15 } \\
\text { minutes }\end{array}$} & \multirow[t]{5}{*}{ Yes } \\
\hline & & & & $\begin{array}{l}\text { The correlation between the } \\
\text { 24-item total and the } \\
\text { omnibus item (item 25) was } \\
0.88 \text {. }\end{array}$ & $\begin{array}{l}\text { The ICC for interrater } \\
\text { reliability of the total of the } \\
\text { first } 24 \text { items was } 0.76 \text {. }\end{array}$ & & \\
\hline & & & & $\begin{array}{l}\text { The correlation between the } \\
24 \text {-item total and study year } \\
\text { was } 0.51 \text {, significant at } P< \\
.0001 \text {. }\end{array}$ & $\begin{array}{l}\text { Nine of the individual items } \\
\text { had individual ICCs between } \\
0.5 \text { and } 0.8 \text { (items } 2,4,6,7,8 \text {, } \\
10,14,15 \text {, and 19). }\end{array}$ & & \\
\hline & & & & \multirow[t]{2}{*}{$\begin{array}{l}\text { The correlation of the } \\
\text { omnibus item and study year } \\
\text { was } 0.47(P<.0001) \text {. }\end{array}$} & $\begin{array}{l}\text { Twelve items had individual } \\
\text { ICCs between } 0.3 \text { and } 0.5 \\
\text { (items } 1,3,5,9,11,12,13,16 \text {, } \\
17,18,20 \text {, and } 24 \text { ), and } 3 \text { items } \\
\text { had individual ICCs below } 0.3 \\
\text { (items } 21,22 \text {, and } 23 \text { ). }\end{array}$ & & \\
\hline & & & & & $\begin{array}{l}\text { Two items had very low } \\
\text { variation between studies ( } 77 \% \\
\text { of studies received a } 0 \text { on item } \\
13 \text { and } 97 \% \text { of studies } \\
\text { received a } 2 \text { on item } 21 \text { ). }\end{array}$ & & \\
\hline
\end{tabular}


Table 1 Characteristics of tools identified in the search update (Continued)

\begin{tabular}{|c|c|c|c|c|c|c|c|}
\hline \multirow[t]{8}{*}{$\begin{array}{l}\text { THE RCT-NATURAL PRODUCTS } \\
\text { TOOL (RCT-NP) [31] }\end{array}$} & \multirow{8}{*}{\multicolumn{2}{|c|}{$\begin{array}{l}\text { Trials of } \\
\text { Natural } \\
\text { products }\end{array}$}} & $\begin{array}{l}\text { The initial list of items for this } \\
\text { study was compiled from } \\
\text { items contained in published } \\
\text { critical appraisal instruments } \\
\text { designed for RCTs of NPs as } \\
\text { well as from items suggested } \\
\text { by the research team. }\end{array}$ & \multirow{8}{*}{$\begin{array}{l}\text { Comparisons with a } \\
\text { published instrument to } \\
\text { evaluate the methodological } \\
\text { quality of RCTs for Natural } \\
\text { product was used (criterion } \\
\text { validity). Similar results were } \\
\text { obtained with both } \\
\text { instruments indicating } \\
\text { criterion validity (Concurrent } \\
\text { validity) } \\
\text { Raters' answers were } \\
\text { compared with investigators } \\
\text { answers to determine } \\
\text { criterion validity as well. No } \\
\text { significant differences } \\
\text { between raters and } \\
\text { investigators (gold standard) } \\
\text { answers were obtained }\end{array}$} & \multirow[t]{8}{*}{ Not reported } & \multirow[t]{8}{*}{$\begin{array}{l}\text { Not } \\
\text { reported }\end{array}$} & \multirow[t]{8}{*}{ Yes } \\
\hline & & & \multirow{3}{*}{$\begin{array}{l}\text { A Delphi process was used to } \\
\text { achieve consensus among a } \\
\text { group of experts as to which } \\
\text { items describing the identity } \\
\text { of an NP were essential to } \\
\text { consider when critically } \\
\text { appraising an RCT of an NP. } \\
\text { The consensus building } \\
\text { process was conducted in } 2 \\
\text { rounds using email. }\end{array}$} & & & & \\
\hline & & & & & & & \\
\hline & & & & & & & \\
\hline & & & $\begin{array}{l}\text { Consensus was considered to } \\
\text { have been reached when } \\
80 \% \text { of participants were in } \\
\text { agreement with an item } \\
\text { being designated as essential } \\
\text { to include in the instrument }\end{array}$ & & & & \\
\hline & & & $\begin{array}{l}\text { A final list of items } \\
\text { considered to be essential by } \\
\text { the study participants and } \\
\text { investigators was assembled. }\end{array}$ & & & & \\
\hline & & & $\begin{array}{l}\text { A systematic review } \\
\text { regarding tools used in to } \\
\text { evaluate quality of NPs trials } \\
\text { was performed. Items from } \\
\text { all of these tools were } \\
\text { compiled }\end{array}$ & & & & \\
\hline & & & $\begin{array}{l}\text { To be designated as essential } \\
\text { to include in the new critical } \\
\text { appraisal instrument, an item } \\
\text { had to meet at least } 1 \text { of the } \\
\text { following } 2 \text { inclusion criteria: } \\
\text { it had to have been } \\
\text { contained in a published } \\
\text { instrument that was } \\
\text { documented as having been } \\
\text { validated or must have had } \\
\text { empirical evidence to } \\
\text { support its inclusion in a } \\
\text { published instrument. }\end{array}$ & & & & \\
\hline
\end{tabular}

A final list of items

considered to be essential by

the study participants and

A systematic review

regarding tools used in to

evaluate quality of NPs trials

was performed. Items from

compiled

be designated as essential

to include in the new critical

appraisal instrument, an item

following 2 inclusion criteria:

ed in a publish

documented as having been

empirical evidence to

published instrument. 
Table 1 Characteristics of tools identified in the search update (Continued)

\begin{tabular}{|c|c|c|c|c|c|c|c|}
\hline \multirow[t]{4}{*}{$\begin{array}{l}\text { A CHECKLIST TO EVALUATE A } \\
\text { REPORT OF A } \\
\text { NONPHARMACOLOGICAL } \\
\text { TRIAL (CLEAR NPT) [51] }\end{array}$} & \multirow[t]{4}{*}{$\begin{array}{l}\text { Health } \\
\text { Research }\end{array}$} & \multirow[t]{4}{*}{10 items and 5 subitems } & $\begin{array}{l}\text { Initial pool of items was } \\
\text { performed from existing } \\
\text { quality tools identified by } \\
\text { Moher et al. and Verhagen } \\
\text { and the CONSORT statement, } \\
\text { users' guides to the medical } \\
\text { literature, and the Cochrane } \\
\text { Reviewers' Handbook. }\end{array}$ & \multirow[t]{4}{*}{$\begin{array}{l}\text { Content validity was } \\
\text { provided by experts in the } \\
\text { field through the Delphi } \\
\text { method }\end{array}$} & \multirow[t]{4}{*}{ Not reported } & \multirow[t]{4}{*}{$\begin{array}{l}10 \\
\text { minutes }\end{array}$} & \multirow[t]{4}{*}{ Yes } \\
\hline & & & $\begin{array}{l}\text { Items specific to NPT trials } \\
\text { identified in a preliminary } \\
\text { study and during informal } \\
\text { interviews of clinicians } \\
\text { working in the field of NPT } \\
\text { were added. }\end{array}$ & & & & \\
\hline & & & $\begin{array}{l}\text { Thirty-eight potential items } \\
\text { were identified. }\end{array}$ & & & & \\
\hline & & & $\begin{array}{l}\text { A Delphi procedure was used } \\
\text { to determine the final items } \\
\text { included in the tool. }\end{array}$ & & & & \\
\hline \multirow[t]{7}{*}{$\begin{array}{l}\text { RISK OF BIAS TOOL (RoB) } \\
{[4,10]}\end{array}$} & \multirow[t]{7}{*}{$\begin{array}{l}\text { Health } \\
\text { Research }\end{array}$} & \multirow{7}{*}{$\begin{array}{l}\text { The risk of bias tool is based } \\
\text { on six domains and } 7 \text { items: } \\
\text { sequence generation, } \\
\text { allocation concealment, } \\
\text { blinding, incomplete } \\
\text { outcome data, selective } \\
\text { outcome reporting, and } \\
\text { "other sources of bias." } \\
\text { Critical assessments on the } \\
\text { risk of bias (high, low, } \\
\text { unclear) are made separately } \\
\text { for each domain. }\end{array}$} & \multirow{7}{*}{$\begin{array}{l}\text { The choice of components } \\
\text { for inclusion in the tool was } \\
\text { based on empirical evidence } \\
\text { showing their association } \\
\text { with effect estimates. }\end{array}$} & $\begin{array}{l}\text { Content validity: items were } \\
\text { included based on empirical } \\
\text { evidence. }\end{array}$ & \multirow{2}{*}{$\begin{array}{l}\text { Interrater agreement for the } \\
\text { individual domains of the } \\
\text { risk of bias tool ranged from } \\
\text { slight }(\mathrm{k}=0.13 \text { for selective } \\
\text { reporting) to substantial } \\
(\mathrm{K}=0.74 \text { for sequence } \\
\text { generation [13]. }\end{array}$} & \multirow[t]{7}{*}{$\begin{array}{l}\sim 21 \\
\text { minutes }\end{array}$} & \multirow[t]{7}{*}{ Yes } \\
\hline & & & & \multirow{3}{*}{$\begin{array}{l}\text { Concurrent validity: A high } \\
\text { degree of correlation was } \\
\text { found between the domains } \\
\text { of risk of bias sequence } \\
\text { generation compared with } \\
\text { Jadad randomisation ( } k=0.79) \\
\text { and risk of bias allocation } \\
\text { concealment compared with } \\
\text { Schulz allocation } \\
\text { concealment ( } k=0.73)[13]\end{array}$} & & & \\
\hline & & & & & $\begin{array}{l}\text { The RoB demonstrated } \\
\text { moderate to substantial } \\
\text { (mean values } 0.56 \text { to } 0.76 \text { ) } \\
\text { agreement on three of } \\
\text { twelve items [59]. }\end{array}$ & & \\
\hline & & & & & The interrater agreement & & \\
\hline & & & & \multirow{2}{*}{$\begin{array}{l}\text { Correlation was low for the } \\
\text { comparisons between the } \\
\text { domains of risk of bias } \\
\text { incomplete outcome data } \\
\text { and the Jadad withdrawal } \\
\text { item, risk of bias overall risk } \\
\text { and total Jadad score, and } \\
\text { risk of bias overall risk and } \\
\text { Schulz allocation } \\
\text { concealment [13] }\end{array}$} & $\begin{array}{l}\text { was fair }(0.40) \text { for selective } \\
\text { outcome reporting and } \\
\text { almost perfect }(0.86) \text { for } \\
\text { sequence generation [62]. }\end{array}$ & & \\
\hline & & & & & $\begin{array}{l}\text { Interrater agreement for the } \\
\text { majority of domains and } \\
\text { overall risk of bias was } \\
\text { moderate }(\mathrm{k}=0.41-0.60) \\
\text { [60]. }\end{array}$ & & \\
\hline & & & & $\begin{array}{l}\text { The correlations between } \\
\text { overall risk of bias } \\
\text { assessments and total Jadad } \\
\text { score }(t=0.04) \text { and allocation } \\
\text { concealment }(t=0.02) \text { were } \\
\text { low [60]. }\end{array}$ & $\begin{array}{l}\text { The inter-rater reliability } \\
\text { across individual domains of } \\
\text { the CCRBT was found to be } \\
0.30 \text {, which is considered } \\
\text { slight agreement between } \\
\text { raters [46]. The inter-rater }\end{array}$ & & \\
\hline
\end{tabular}

come data, selective

"ritical assessments on the

nclear) are made separately

low $[60]$ 
reliability of the final grade

assigned to each paper by

this tool was ICC $=0.58(95 \%$

Cl 0.20-0.81)[61]

There was very poor

agreement between the

agreement between the

Practice Project Quality

Assessment Tool (EPHPP)

and the RoB tool in the final

grade assigned to each

study $($ kappa $=0.006)[61]$

The inter-rater reliability was

substantial for sequence

generation ( $k=0.79)$ and fair

for the other 5 items $(k=0.24$

0.37). Interrater reliability

between consensus

evaluations across rater pairs

was fair for allocation

concealment and "other

sources of bias" ( $k=0.37-0.27)$

and moderate for sequence

generation ( $k=0.60)$. [62]

95\% Cl= 95\% confidence interval, CONSORT Consolidated Standards of Reporting of Trials, ICC intraclass correlation coefficient, $k$ kappa, NP natural products, NPT natural products trials, RCT randomized controlled trial, $R o B$ risk of bias. 
Table 2 Summary of the quality of measurement properties of quality tools from our previous systematic review and this update

\begin{tabular}{|c|c|c|c|c|c|c|}
\hline Scale & $\begin{array}{c}\text { Internal } \\
\text { consistency }\end{array}$ & $\begin{array}{c}\text { Face } \\
\text { validity }\end{array}$ & $\begin{array}{l}\text { Content } \\
\text { validity }\end{array}$ & $\begin{array}{l}\text { Criterion } \\
\text { Validity* }\end{array}$ & $\begin{array}{l}\text { Construct } \\
\text { validity }\end{array}$ & $\begin{array}{c}\text { Reproducibility } \\
\text { (agreement/reliability) }\end{array}$ \\
\hline \multicolumn{7}{|l|}{ TOOLS FOR PT } \\
\hline Jadad Tool [37] & - & + & + & + & + & + \\
\hline Maastricht Tool [38] & - & + & - & + & - & + \\
\hline Delphi Tool [39] & - & + & + & + & - & + \\
\hline PEDro Tool $[40,41]$ & - & + & + & - & - & + \\
\hline Maastricht-Amsterdam Tool [42] & - & + & + & - & - & + \\
\hline Van Tulder Tool [43] & - & + & + & + & - & + \\
\hline Bizzini tool [44] & - & + & + & - & - & + \\
\hline \multicolumn{7}{|l|}{ TOOLS FOR GENERAL HEALTH RESEARCH } \\
\hline \multicolumn{7}{|l|}{ Tools from previous systematic review } \\
\hline Chalmers tool [45] & - & + & + & + & - & + \\
\hline Reisch Tool [46] & - & + & - & + & - & - \\
\hline Andrew tool [47] & - & + & - & - & - & + \\
\hline Imperiale tool [48] & - & + & - & + & - & - \\
\hline Detsky tool [49] & - & + & - & + & - & + \\
\hline Cho Tool [50] & - & + & - & + & - & + \\
\hline Balas tool [51] & - & + & - & - & - & - \\
\hline Sindhu tool [52] & - & + & + & + & - & + \\
\hline Downs and Black tool [53] & + & + & + & + & - & + \\
\hline Nguyen tool [54] & - & + & - & - & - & - \\
\hline Oxford pain validity tool [55] & - & + & - & - & - & - \\
\hline Arrive tool [56] & - & + & - & - & - & + \\
\hline CONSORT tool [57] & - & + & + & - & - & + \\
\hline Yates Tool [58] & - & + & + & - & + & + \\
\hline \multicolumn{7}{|l|}{ New tools identified in search update } \\
\hline $\begin{array}{l}\text { Cochrane Collaboration Depression, Anxiety, and } \\
\text { Neurosis (CCDAN) [34,35] }\end{array}$ & + & + & + & - & + & + \\
\hline $\begin{array}{l}\text { The Randomized Controlled Trial Psychotherapy Quality } \\
\text { Rating Tool (RCT-PQRS Tool) [32,33] }\end{array}$ & + & + & + & - & + & + \\
\hline RCT-Natural Products Tool (RCT-NP) [31] & - & + & + & + & - & - \\
\hline $\begin{array}{l}\text { CLEAR NPT (Checklist to evaluate a report of a } \\
\text { nonpharmacological trial [36] }\end{array}$ & - & + & + & - & - & - \\
\hline Risk of Bias Tool (RoB) $[4,10]$ & - & + & + & + & + & + \\
\hline
\end{tabular}

+Quality of measurements properties were based on guidelines established by Terwee et al. [13].

$(+)$ : criterion accomplished.

$(-)$ : Criterion not accomplished.

* In all cases, criterion validity was established with "no gold standard tools".

PT physical therapy, $R C T$ randomized controlled trial.I

were the most frequently used items among PT tools $(86 \%, 6 / 7)$ (Additional files 5 and 6, Figures 2 and 3). The second most frequently used items in PT tools were: reporting of withdrawals and dropouts, method of randomization concealment, description of inclusion/exclusion, reporting of descriptive measures for point estimates, blinding of therapist, and blinding of participants (71\%, 5/7 tools) (Figures 2 and 3).
Inclusion of the following items was significantly more frequent in PT tools compared with general health research tools: "intention to treat" $(\mathrm{p}=0.014)$, "withdraws and drop outs acceptable" ( $\mathrm{p}<0.001)$, and "baseline comparability" ( $\mathrm{p}=0.027)$.

When RoB items were individually examined, we found that sequence generation and allocation concealment were included in 5 of the 7 PT tools (Figure 4). 


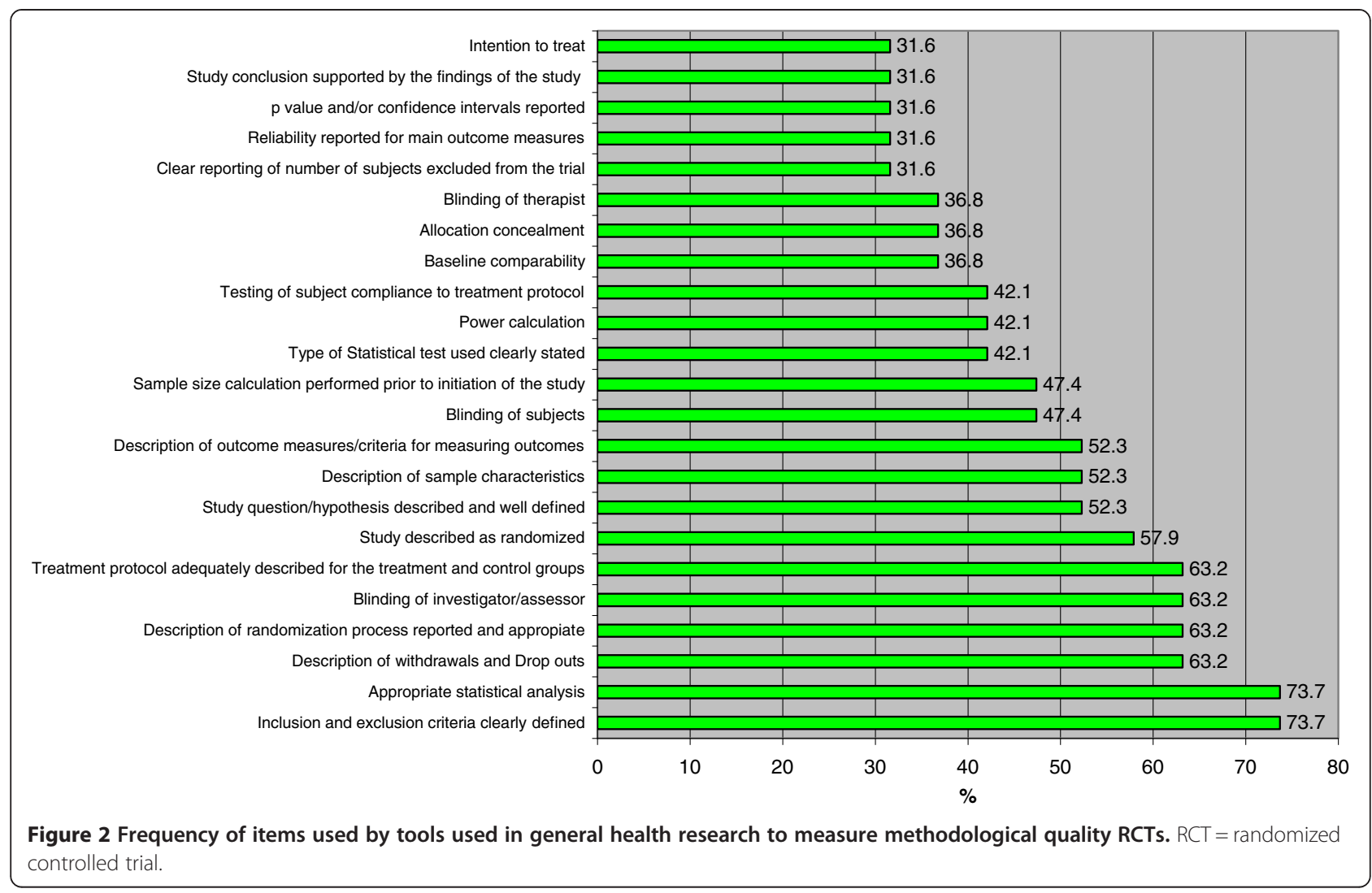

Only four PT tools evaluated whether randomization was performed. Twelve (63\%) general health research tools included randomization whereas seven (37\%) included an item for allocation concealment. Further, fewer of the general health research tools included items related to blinding compared with the PT tools: blinding of participants (47\% versus $71 \%$ ) and blinding of outcome assessors (63\% versus $86 \%$ ). Intention to treat analysis, a component of the incomplete outcome data domain in the RoB tool was more frequently used in PT tools $(86 \%)$ compared with general health research tools (32\%). Other items related to incomplete outcome data in the RoB tool are "description of withdrawals and drop outs" and "appropriateness of withdrawal/drop outs rate". Compared with the general health research tools (63\%), a larger proportion of PT tools (71\%) included items for the description of withdrawals and drop outs. In contrast, none of the general health research tools included an item about whether the withdrawal/drop-out rate was acceptable compared with $57 \%$ of the PT tools. Another quality item used in the RoB tool is baseline comparability. This item was included in $86 \%$ of PT tools compared with $37 \%$ of the general health research tools. In general, PT tools appeared more similar in content to the RoB tool than those used for general health research (Figure 4).

\section{Reporting versus conduct items and threats to validity and precision}

Of the 130 items included in the general health research tools, $62(48 \%)$ evaluated trial "reporting" whereas 60 items (46\%) evaluated "conduct" (i.e. methodological quality or risk of bias). Eight items (6\%) were considered to evaluate both quality of reporting and conduct of trials (i.e. sample representativeness and description of participants source, description of randomization process reported and appropriate; testing of subject compliance to treatment protocol /report of compliance; therapist training and level of experience in the treatment(s) under investigation; validity, reliability and responsiveness of the outcome measures reported; post-hoc power calculations and confidence intervals reported).

Classification of items from general health research tools according to type of bias and threats to precision was as follows: selection bias (25 items, 19\%); performance bias (six items, 4.6\%); performance and detection bias (six items, 4.6\%); performance bias and contamination (seven items, 5.4\%); performance bias and compliance (two items, 1.6\%); attrition bias (ten items, 7.8\%); information bias (six items, 4.6\%); detection bias (five items, 3.8\%); reporting bias (17 items, $13 \%$ ); threats to precision (four items, 3.1\%); statistical bias (three items, $2.3 \%$ ); threats to precision and statistical bias (two items, 


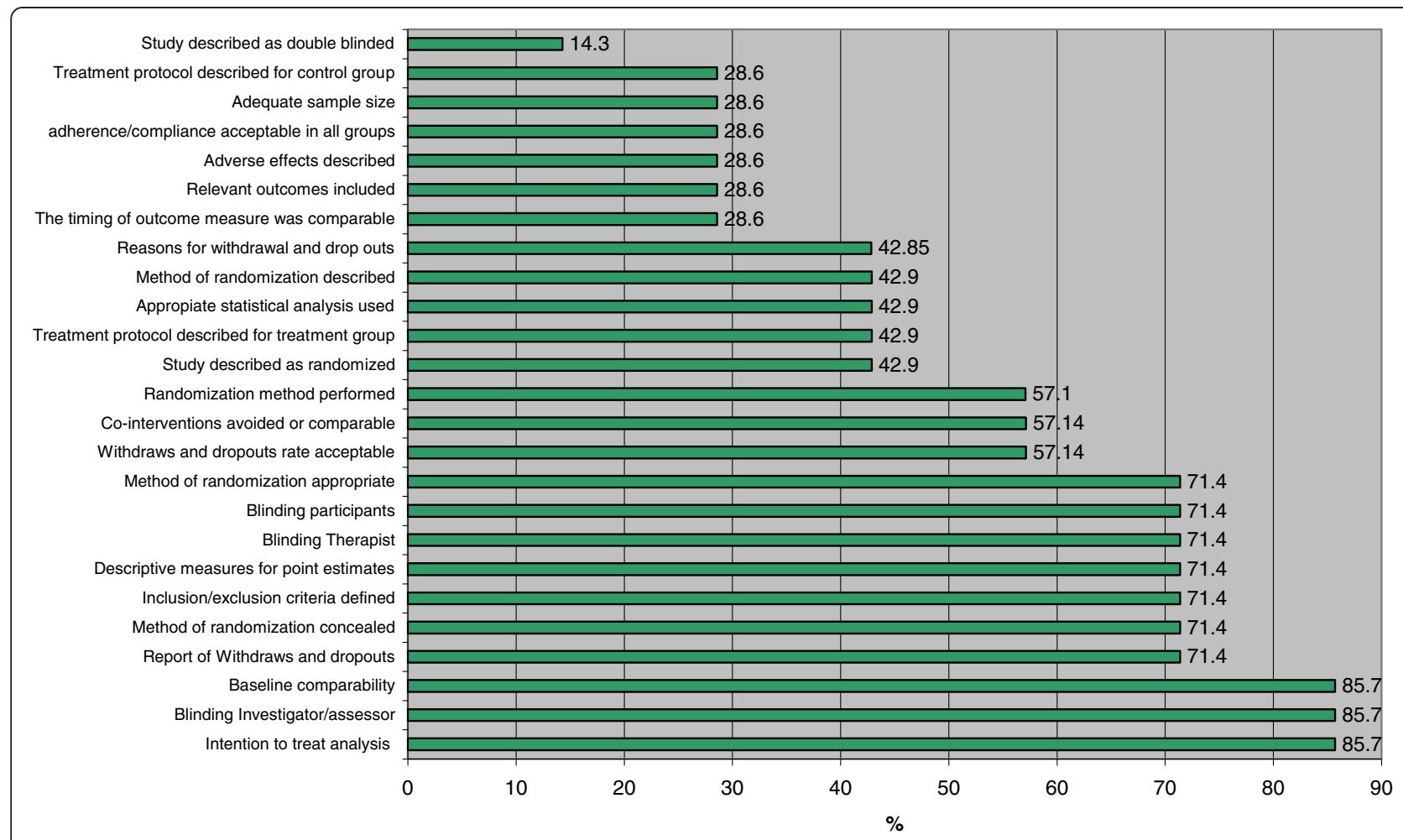

Figure 3 Frequency of items used from tools used in PT research to measure methodological quality of RCTs. PT= physical therapy; $\mathrm{RCT}=$ randomized controlled trial. Results expressed as percentages.

1.6\%); multiple biases (three items, $2.3 \%$ ); and other (i.e., not classified as related to threats to validity or precision) (27 items, 21\%) (Additional file 5).

Of the 48 items included in PT tools, 16 (33.3\%) evaluated trial "reporting" whereas 28 (58.3\%) evaluated "conduct". Four items (8.3\%) were considered to evaluate both quality of trial reporting and conduct: testing/report subject compliance to treatment protocol, and validity, reliability and responsiveness of the outcome measures reported.

The classification of items from PT tools according to type of bias and threats to precision was as follows: selection bias (10 items, 21\%); performance and detection bias (five items, 10\%); performance bias only (six items, 135\%); performance and contamination bias (two items, $4.2 \%$ ); performance and compliance bias (two items, 4.2\%); information bias (five items, $10 \%$ ); attrition bias (eight items, 17\%); detection bias (three items, 6.3\%); reporting bias (three items, 6.3\%); threats to precision (two items, 4.2\%); and statistical bias (1 item, 2.1\%). (Additional file 6).

\section{Frequency of citations of quality tools}

The number of citations per quality tool since its inception and after 2007 are detailed in Table 3. The Jadad scale was, by far, the most cited and used tool with 5,326 citations from inception (i.e., year 1996) to July 4, 2013. The second most cited tool was the Downs and Black tool, with 962 citations since its introduction in 1998. Other tools frequently cited were: PeDro, Delphi, and Chalmers tools $(651,625$, and 584 citations from inception, respectively), followed closely by the Van Tulder (560 citations) and Maastricht-Amsterdam (360 citations) tools. Among the most frequently cited tools, a larger proportion (5/7) were PT tools compared with only two of the 19 general health research tools (i.e. Jadad and Chalmers). The relative number of citations for the tools after 2008 was similar to those of previous years. Particularly, the use of the Jadad tool (i.e. number of citations from 2007 to July 4, 2013: 3,672) did not show a decrease (in terms of absolute numbers of citations) after the inception of the RoB tool in 2008 (Table 3). Tracking of the RoB tool showed that it has been cited approximately 1230 times since inception. This number is likely an underestimate because of the challenges described above with respect to tracking the Cochrane Handbook chapter that first described the tool. However, this information provides a reference point to track usage of the RoB tool over time. 


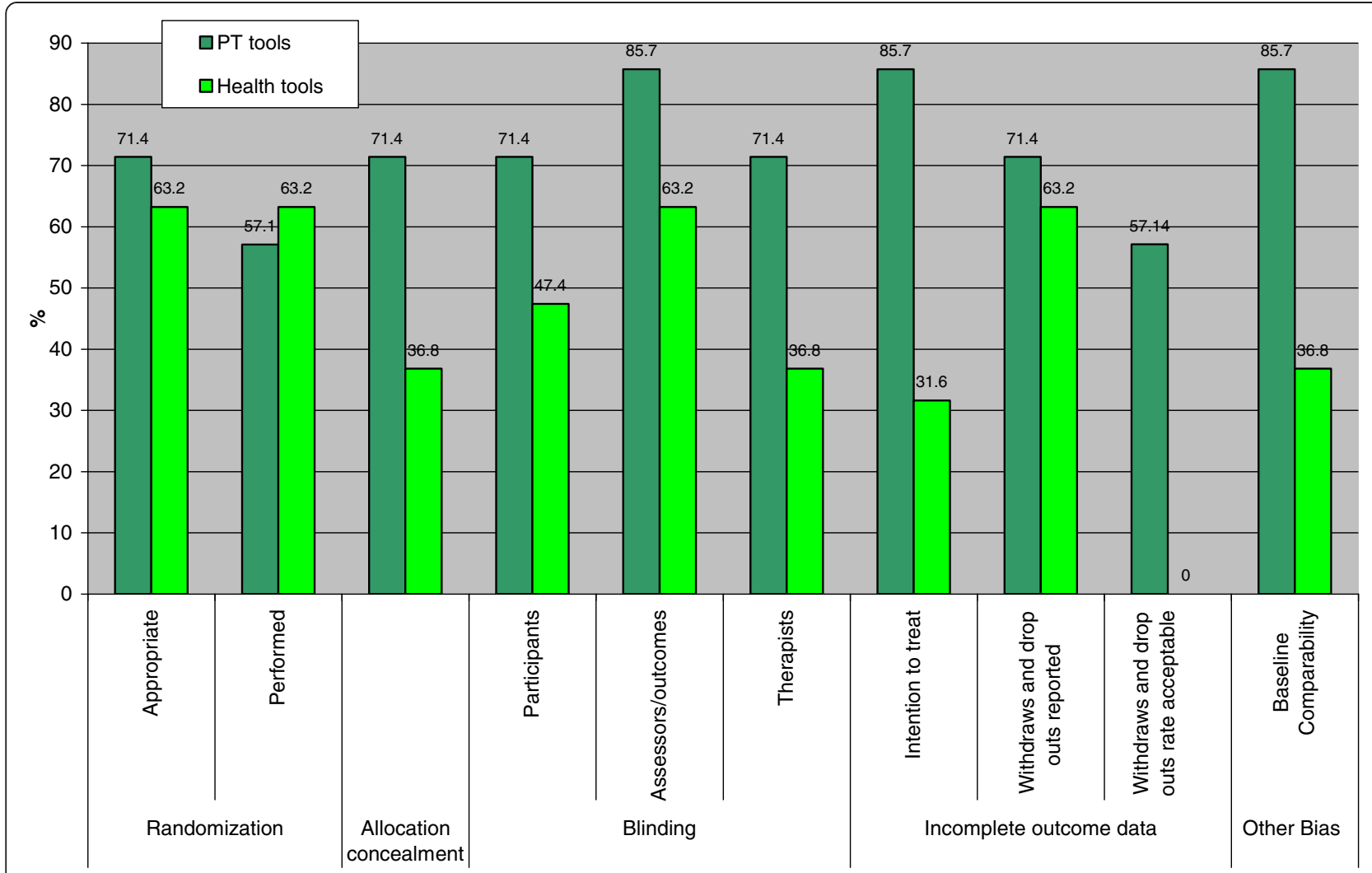

Figure 4 Comparison between RoB tool domains and items from PT and health sciences tools. PT = physical therapy; RoB $=$ risk of bias. Results expressed as percentages.

\section{Discussion}

This study examined tools and individual items used in general health and PT research to assess the quality of RCTs. A variety of tools are still widely used despite criticisms raised regarding their limitations $[8,63]$. This finding is consistent with previous reviews on this topic that have identified inconsistencies in the use of quality tools $[5,6,18]$. There is extensive variation in individual items included across quality assessment tools. Many of these items may not be indicators of bias nor related to overor under-estimations of treatment effects. Moreover, there is lack of empirical evidence supporting the association of many individual quality items with changes in the magnitude and direction of treatment effects. This finding raises important concerns in the field of quality assessment regarding the appropriateness of evaluating the evidence based on the use of these tools and items.

Results of this study agree with those of Deschartres et al. [19] which found that a large number of tools have been used in reviews that assessed the quality and reporting of RCTs. According to Deschartres et al. [19], ambiguity and lack of a unique definition of trial "quality" accounts for the heterogeneity of quality assessment tools. According to Verhagen et al. [2], methodological quality assessment involves the evaluation of internal validity (the degree to which the study design, conduct and analysis have minimized biases), external validity (the extent to which study results are generalizable beyond the experimental situation), and statistical analysis of primary research. According to The Cochrane Collaboration [10], internal validity of a trial is linked to "risk of bias" and it should be the primary focus of quality assessment since external validity differs upon context. In addition, "quality of reporting" is commonly used as a proxy for trial quality, which has complicated the construct of "quality" even more.

A clear and consistent definition of "quality" across health research areas is necessary to advance the field of quality assessment. Furthermore, concepts such as internal validity, external validity, and quality of reporting should be explicitly and clearly defined for the constructs that the individual items are meant to address. Finally, items assessing the methodological quality (or internal validity) of RCTs should be based on empirical evidence of their association with treatment effects. 
Table 3 Frequency of citations of Quality Tools in Scopus Database

Tool All years until From January 2007- Year 2007 Year Year Year Year Year Year 2013 Until Subject area most used July 4,2013 July 4,2013 before RoB 20082009201020112012 July 4, 2013

\section{PT TOOLS}

Jadad [37]

Maastricht [38]

Delphi [39]

PEDro $[40,41]$

Maastricht-Amsterdam [42]

Van Tulder [43]

Bizzini [44]

GENERAL HEALTH RESEARCH TOOLS

Tools From Previous Systematic Review

Chalmers [45]

Reisch [46]

Andrew [47]

Imperiale [48]

$\begin{array}{cc}5326 & 3672 \\ 106 & 45 \\ 625 & 454 \\ 651 & 555 \\ 360 & 158 \\ 560 & 482 \\ 65 & 50\end{array}$
too

Detsky [49]

Cho [50]

Balas [51]

Sindhu [52]

Downs and Black [53]

Nguyen [54]

Oxford pain validity tool [55]

Arrive [56]

CONSORT [57]

Yates [58]

$\begin{array}{cc}584 & 151 \\ 56 & 26 \\ 10 & 0 \\ 141 & 47 \\ 281 & 120 \\ 109 & 30 \\ 37 & 5 \\ 31 & 11 \\ 962 & 783 \\ 84 & 63 \\ 143 & 49 \\ 23 & 6 \\ 184 & 124 \\ 35 & 33\end{array}$

$\begin{array}{cccccc}393 & 468 & 616 & 514 & 634 & 706 \\ 3 & 6 & 10 & 5 & 7 & 9 \\ 39 & 65 & 71 & 77 & 87 & 75 \\ 49 & 52 & 87 & 91 & 101 & 108 \\ 34 & 36 & 23 & 21 & 21 & 19 \\ 43 & 58 & 101 & 86 & 65 & 93 \\ 4 & 15 & 7 & 6 & 9 & 4\end{array}$

Medicine

Medicine/health professions

Medicine/health professions

Health professions/ Medicine

Medicine/health professions

Medicine/health professions

Medicine/health professions

Medicine/Psychology

Medicine/ Nursing

Medicine

Medicine/ Pharmacology,

Toxicology and Pharmaceutics

Medicine/ Biochemistry/

Nursing

Medicine/ Pharmacology,

Toxicology and Pharmaceutics

Medicine

Medicine/Nursing

Medicine/Nursing

Dentistry/Medicine

Medicine/Neuroscience

Medicine

Medicine/Biochemistry

Medicine/Neuroscience 
Table 3 Frequency of citations of Quality Tools in Scopus Database (Continued)

\section{NEW TOOLS}

Cochrane Collaboration Depression,

Anxiety, and Neurosis (CCDAN) $[34,35]$

The Randomized Controlled Trial

Psychotherapy Quality Rating (RCT-PQRS)

[32,33]

RCT-Natural Products (RCT-NP) [31]

CLEAR NPT (Checklist to evaluate a report of

a nonpharmacological trial [36]

Risk of Bias (Scopus Track) Higgins et al

2011 [4]

Risk of Bias(Google Scholar) Chapter 8:

Cochrane Handbook (2008-July4, 2013) [10]

Total RoB

59

30

44

30

3

102

124

*This number could include duplicates; RoB risk of bias. 
The number of items across quality tools is large; 130 and 48 items have been used by tools in general health and PT research, respectively. Some items are subjective, confusing, and lack a clear definition (e.g., subjects appropriate to study questions, discussion of bias resulting from non-blinding assessment). These factors make the evaluation of individual items challenging and likely contribute to low inter-rater agreement. Many quality items relate to "reporting" rather than "conduct" of trials; approximately half of the items from these tools relate to reporting only. This finding is consistent with results described by Deschartres et al. [19], in which $25 \%$ of methodological reviews stated that RCTs reported details of sample size calculation, but only $6 \%$ reported on adequacy of the sample size. Although clear reporting is necessary to assess the quality of trial conduct, a focus on quality of reporting can hide differences in trial conduct and lead to under- or over-estimation of the methodological quality [64].

\section{Comparison of items between PT and general health research tools with RoB tool}

We found that items frequently included in the PT tools were more closely linked to items/domains included in the RoB tool than those of general health research tools. This result suggests that PT tools are more closely linked to an examination of bias than the general health research tools.

Empirical evidence has supported many items in the RoB tool. There is a substantial interest in investigating which methodological features of RCTs are associated with treatment effects. Evidence informing this association comes mainly from RCTs in the area of medicine and is based primarily on evaluations of dichotomous outcomes $[12,14,15]$. Therefore, empirical evidence on the relationship between trial quality and treatment effects may not be readily applicable to other health research areas such as PT and other areas of rehabilitation. Morever, information regarding the importance of including certain items in quality tools within different clinical areas is limited. As mentioned previously, RCTs in the area of PT have distinct characteristics compared with pharmacological trials conducted in medicine. PT interventions are complex interventions [20]; they comprise certain characteristics such as the type of therapy and its intensity, a standardized or individually tailored approach, and the skills and experience of the therapists, that are likely to affect trial results. In addition, because of the nature of certain PT interventions (e.g., manual therapy, exercises), blinding of therapists and/or patients is not always possible. Appropriate blinding of study participants and all key study personnel is unlikely to be accomplished for most PT trials; however, blinding of outcome assessment has been commonly used as a proxy quality measure without validation. Therefore, more empirical evidence on trial bias is needed in the area of PT to determine which factors are likely to affect treatment effect estimates and thus provide accurate results for the clinical community. Further research should examine the appropriateness of using certain items/ domains when evaluating the risk of bias of primary research in a variety of health areas. This information would provide clear benchmarks to assess the quality or risk of bias of primary research included in SRs and meta-analysis, and ultimately strengthen the evidence for decision-making in all areas of health care.

The RoB tool is recommended by The Cochrane Collaboration. Some groups within the Collaboration have developed their own tools and have not yet adopted the RoB approach (e.g. Cochrane Bone, Joint and Muscle Trauma Group). Other Cochrane groups have modified the RoB tool for their own purposes (i.e. Cochrane Back Review Group, Cochrane Renal Review Group). The RoB tool was developed more recently than many of the other tools; current research $[9,13]$ recommends further testing of its psychometric properties and validation of the tool in a wide range of research fields. Additional guidelines will help users in applying and interpreting the results of the RoB tool.

\section{PT and general health research tool items and threats to validity and precision}

Most items from general health research and PT tools were classified according to one or more categories of threats to validity or precision; however, some items could not be placed in any category. For example, the item "study question/hypothesis/purpose described and well defined" was not linked to any type of bias and was found irrelevant for study quality. Nevertheless, this item was included in 10 (53\%) health research tools. This situation raises concerns about the usefulness of certain items to determine trial quality; therefore, these types of items should be carefully considered when deciding whether they should be part of these tools.

Classifying quality items was a complex task due to unclear descriptions of the items and lack of empirical evidence linking these items to bias. The number of items that was linked to different types of bias varied by tool. For example, a high percentage of items dealt with selection bias (approximately 19\% of general health and $21 \%$ of PT tools). In contrast, attrition bias was more frequently represented in items found in PT (17\%) compared with general health research $(7 \%)$ tools. These results call for an in-depth analysis of individual items of tools that evaluate trial quality or risk of bias of RCTs in health research in order to provide a more complete assessment of their internal validity. 


\section{Tools most cited}

The Jadad scale [37] is the most frequently cited tool in health sciences research despite criticisms regarding its lack of responsiveness [8] and applicability to other health research areas such as PT and rehabilitation [5]. Herbison et al. [8], found that the Jadad scale might not be responsive enough to distinguish among different levels of trial quality. The use of the Jadad scale has been discouraged in many areas of health research. The discordance between recommendations against using the Jadad scale and its ongoing use is a matter of concern and reasons for this discrepancy should be further explored. It is likely that the Jadad tool is popular among SR authors because it is simple and requires little time to apply [13].

None of the other quality tools used in general health research and PT is as highly cited as the Jadad tool. Some tools are specific to certain areas (e.g., PT, nursing, psychology, pharmacology); most of them are long instruments and require a greater amount of time to complete; and some lack clear guidelines for item assessment, which can discourage their use.

\section{Strengths and limitations}

To the best of our knowledge, this study is the first to exhaustively explore the type and frequency of individual items included in tools that evaluate the quality or risk of bias of RCTs in health research. A comprehensive search was performed for all published research in this area, with no language restrictions, and using several strategies (i.e., manual search, Scopus) to identify relevant literature. However, because of indexing problems of research on the evaluation of quality assessment tools for RCTs [19], some studies may have been missed; this would not likely change our general findings.

Data extraction and item classification was performed independently by two researchers with disagreements resolved by consensus. The process of classifying items was somewhat subjective; therefore, classification of some items may be debated. Difficulties in classifying items as potentially linked to bias have been acknowledged in previous studies that analyzed bias in different types of research designs [25,28,65].

We used Scopus database to track all original papers describing quality tools. We acknowledge that this approach is only an indirect measure of the usage of quality tools and should not be interpreted as absolute indicator of usage over time.

\section{Conclusion}

There is a considerable number of tools to evaluate the quality of RCTs in health research. There is extensive variation in the number of individual items across quality assessment tools and an apparent lack of agreement between PT and general health research tools in the type of items that are included. There is a need for clarity and consistency of the constructs evaluated by items in quality assessment tools, particularly for aspects related to internal validity, external validity, precision, and quality of reporting. The selection of items to assess internal validity, or risk of bias, should be based on empirical evidence of an association with distortions of treatment effects. Finally, tools and items should undergo a thorough validation process to examine their psychometric properties. Future studies in this area should investigate which items are linked to bias through empirical evidence or psychometric testing. This information will be valuable for the field of knowledge synthesis.

\section{What is new? \\ Key findings}

There is extensive item variation across tools that evaluate the risk of bias of RCTs. There is a lack of empirical evidence to support the association with bias for many items.

What this adds to what is known: Although some studies have previously addressed the use of tools for quality assessment of RCTs, this is the first study that exhaustively explores the type and frequency of items included in different tools that evaluate the risk of bias of RCTs in health research. The number of items included across quality tools is large: 130 and 48 different items have been used by general health research and physical therapy (PT) tools, respectively. Many items are used without a clear identification of their link to bias, or internal validity. The frequency of use of these items varies according to health area (as demonstrated by our comparison between PT and general health research), which suggests a lack of agreement regarding their relevance to trial quality or risk of bias.

What is the implication, what should change now? Results of this study call for an in-depth empirical analysis of the items that should be used to assess risk of bias of RCTs in health research. This information is urgently needed to develop guidelines for the design, conduct, and implementation of trials. In addition, this information is important for systematic reviewers and metaanalysts to evaluate the risk of bias of intervention trials in different areas of health research.

\section{Additional files}

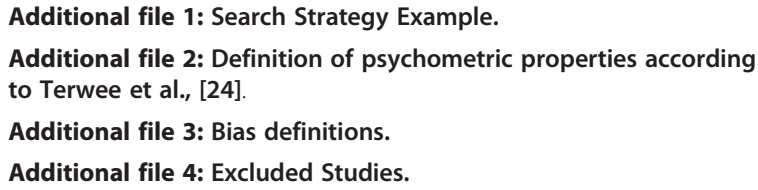




\section{Additional file 5: Heath Sciences Tools and items to Measure Methodological Quality of RCTs.}

Additional file 6: Tools and Items to Assess Quality of RCTs in Physical Therapy.

\section{Abbreviations}

CCDAN: Cochrane collaboration depression, anxiety, and neurosis; PT: Physical therapy; RCT: Randomized controlled trial; RCT-NP: Randomized controlled trial -natural products; RCT-PQRS: Randomized controlled trial psychotherapy quality rating scale; RoB: Risk of bias; SRs: Systematic reviews.

\section{Competing interests}

The authors declare that they have no competing interests.

\section{Authors' contributions}

$\mathrm{AO}$ conceived of the study, designed the study, and drafted the manuscript $\mathrm{AO}, \mathrm{JF}, \mathrm{MO}$ and $\mathrm{HS}$ contributed to data collection data analysis, and interpretation. LH provided feedback on the concept and research design and participated in interpretation of data. All authors critically revised the manuscript and provided final approval of the version to be published.

\section{Author's information}

Susan Armijo-Olivo has a Bsc in Physical therapy (PT) from the Pontifical University Catholic of Chile, a MSc PT and a PhD in Rehabilitation Sciences from the University of Alberta. Her major field of research is diagnosis, evaluation, and treatment of patients with musculoskeletal pain especially temporomandibular disorders and cervical spine disorders along with physical therapy evidence based practice. She currently is a postdoctoral fellow at the CLEAR (Connnecting Leaadership and Research Program in the Faculty of Nursing at the University of Alberta. Her post-doctoral project will focus on the methodological predictors of effect size estimates in PT trials. This research is critical to accurately provide conclusions for health care and decision making. This project will be an important contribution to the area of knowledge synthesis and translation in the PT field and allied health professions.

\section{Acknowledgements}

Dr. Susan Armijo-Olivo is supported by the Canadian Institutes of Health Research (CIHR) through a full-time Banting fellowship, the Alberta Innovates Health solution through an incentive award and the STIHR Training Program from Knowledge Translation (KT) Canada, and the University of Alberta. Dr. Humam Saltaji is supported through a Clinician Fellowship Award by Alberta Innovates - Health Solutions (AIHS), the Honorary Izaak Walton Killam Memorial Scholarship by the University of Alberta, and the Honorary WCHRI Award by the Women and Children's Health Research Institute (WCHRI) . Dr. Lisa Hartling is supported by a Canadian Institutes of Health Research New Investigator Salary Award. This project was funded by the Physiotherapy Foundation of Canada (PFC) through a B.E. Schnurr Memorial Fund Award, AlHS through a knowledge translation initiative grant, the Knowledge Translation (KT) Canada Research Stipend Program, the CIHR Banting program and the University of Alberta.

The authors of this study thank staff at the Alberta Research Centre for Health Evidence who helped with data collection: Melanie Muise, Walie Atkary, and Alyssa Guthrie.

\section{Author details}

${ }^{1}$ Postdoctoral Fellow, CLEAR (Connecting Leadership and Research) Outcomes Research Program, University of Alberta, 5-115A Edmonton Clinic Health Academy (ECHA), 11405 - 87 Avenue, Edmonton, Alberta T6G 1C9 Canada. ${ }^{2}$ Faculty of Rehabilitation Medicine, Department of Physical Therapy, University of Alberta, 3-48 Corbett Hall, Edmonton T6G 2G4, Canada. ${ }^{3}$ Department of Physical Therapy, Catholic University of Maule, Talca, Chile. ${ }^{4}$ School of Public Health, University of Alberta, Institute of Health Economics, Edmonton, Alberta, Canada. ${ }^{5}$ School of Dentistry, Faculty of Medicine and Dentistry, University of Alberta, Edmonton, Alberta, Canada. ${ }^{6}$ Alberta Research Centre for Health Evidence, Department of Pediatrics, Faculty of Medicine and Dentistry, University of Alberta, Edmonton, Alberta, Canada.

Received: 26 December 2012 Accepted: 12 September 2013 Published: 17 September 2013

\section{References}

1. Khan K, Ter Riet G, Popay J, Nixon J, Kleijnen J: Satge II. Conducting the Review. Phase 5 Study Quality Assessment. In Undertaking Systematic Reviews of research Effectiveness CRD's Guidance for those carrying out or commissioning reviews. York: Centre for Reviews and Dissemination; 2001:1-20.

2. Verhagen AP, de Vet HC, de Bie RA, Boers M, van den Brandt PA: The art of quality assessment of RCTs included in systematic reviews. $J$ Clin Epidemiol 2001, 54(7):651-654.

3. Juni $P$, Altman DG, Egger M: Systematic reviews in health care: Assessing the quality of controlled clinical trials. BMJ 2001, 323(7303):42-46.

4. Higgins JPT, Altman DG, Goetzsche PC, Juni P, Moher D, Oxman AD, Savovic Ä J, Schulz KF, Weeks L, Sterne JAC: The Cochrane Collaboration's tool for assessing risk of bias in randomised trials. BMJ 2011, 343(7829):d5928. 10.1136/bmj.d5928.

5. Armijo-Olivo S, Macedo LG, Gadotti IC, Fuentes J, Stanton T, Magee DJ: Scales to assess the quality of randomized controlled trials: a systematic review. Phys Ther 2008, 88(2):156-175.

6. Moher D, Jadad AR, Nichol G, Penman M, Tugwell P, Walsh S: Assessing the quality of randomized controlled trials: an annotated bibliography of scales and checklists. Control Clin Trials 1995, 16(1):62-73.

7. Colle F, Rannou F, Revel M, Fermanian J, Poiraudeau S: Impact of quality scales on levels of evidence inferred from a systematic review of exercise therapy and low back pain. Arch Phys Med Rehabil 2002, 83(12):1745-1752.

8. Herbison P, Hay-Smith J, Gillespie WJ: Adjustment of meta-analyses on the basis of quality scores should be abandoned. J Clin Epidemiol 2006, 59(12):1249-1256.

9. Armijo-Olivo S, Stiles C, Hagen N, Biondo P, Cummings G: Assessment of study quality for systematic reviews: a comparison of the Cochrane Collaboration Risk of Bias tool and the Effectve Public Health Practice Project Quality Assessment Tool: methodological research. J Eval Clin Pract 2012, 18(1):12-18.

10. Higgins J, Altman D: Chapter 8: Assessing risk of bias in included studies In Cochrane Handbook for Systematic Reviews of Interventions version 50. Edited by Higgins J, Green S. Chichester, UK: John Wiley \& Sons, Ltd; 2008.

11. Pildal J, Hrobjartsson A, Jorgensen KJ, Hilden J, Altman DG, Gotzsche PC: Impact of allocation concealment on conclusions drawn from metaanalyses of randomized trials. Int J Epidemiol 2007, 36(4):847-857.

12. Wood L, Egger M, Gluud LL, Schulz KF, Juni P, Altman DG, Gluud C, Martin RM, Wood AJG, Sterne JAC: Empirical evidence of bias in treatment effect estimates in controlled trials with different interventions and outcomes: Meta-epidemiological study. BMJ 2008, 336(7644):601-605.

13. Hartling L, Ospina M, Liang Y, Dryden DM, Hooton N, Seida JK, Klassen TP: Risk of bias versus quality assessment of randomised controlled trials: cross sectional study. BMJ 2009, 339(7728):1017.

14. Moher D, Pham B, Jones A, Cook DJ, Jadad AR, Moher M, Tugwell P, Klassen TP: Does quality of reports of randomised trials affect estimates of intervention efficacy reported in meta-analyses? Lancet 1998, 352(9128):609-613

15. Schulz KF, Chalmers I, Hayes RJ, Altman DG: Empirical evidence of bias: Dimensions of methodological quality associated with estimates of treatment effects in controlled trials. JAMA 1995, 273(5):408-412.

16. Assessing risk of bias in included studies. http://bmg.cochrane.org/assessingrisk-bias-included-studies.

17. Delgado-Rodriguez M, Llorca J: Bias. J Epidemiol Commun Health 2004 58(8):635-641.

18. Katrak P, Bialocerkowski AE, Massy-Westropp N, Kumar S, Grimmer KA: A systematic review of the content of critical appraisal tools. BMC Med Res Methodol 2004, 4(1):22.

19. Dechartres A, Charles P, Hopewell S, Ravaud P, Altman DG: Reviews assessing the quality or the reporting of randomized controlled trials are increasing over time but raised questions about how quality is assessed. J Clin Epidemiol 2011, 64(2):136-144.

20. Kunz R, Autti-Ramo I, Anttila H, Malmivaara A, Makela M: A systematic review finds that methodological quality is better than its reputation but can be improved in physiotherapy trials in childhood cerebral palsy. J Clin Epidemiol 2006, 59(12):1239-1248.

21. Streiner D, Norman G: Validity. In Health Measurements Scales. Edited by Streiner D, Norman G. Oxford: Oxford University Press; 2004:172-193.

22. Streiner D, Norman G: Reliability. In Health Measurements Scales. Edited by Streiner D, Norman G. Oxford: Oxford University Press; 2004:126-152. 
23. Streiner D, Norman G: Measuring Change. In Health Measurements Scales. Edited by Streiner D, Norman G. Oxford: Oxford University Press; 2004:194-212.

24. Terwee CB, Bot SDM, de Boer MR, van der Windt DAWM, Knol DL, Dekker J, Bouter LM, de Vet HCW: Quality criteria were proposed for measurement properties of health status questionnaires. J Clin Epidemiol 2007, 60(1):34-42.

25. Whiting P, Rutjes AWS, Reitsma JB, Glas AS, Bossuyt PMM, Kleijnen J: Sources of variation and bias in studies of diagnostic accuracy: a systematic review. An Intern Med 2004, 140(3):189-202.

26. Sackett DL: Bias in analytic research. J Chronic Dis 1979, 32(1-2):51-68.

27. Viswanathan M, Berkman ND: Development of the RTI item bank on risk of bias and precision of observational studies. J Clin Epidemiol 2011, 65(2):163-178.

28. Hayden JA, Cotte P, Bombardier C: Evaluation of the quality of prognosis studies in systematic reviews. An Intern Med 2006, 144(6):427-437.

29. Lash TL, Fox MP, Fink AK: Multiple Bias Modeling: Applying Quantitatvie Bias Analysis to. Springer New York: Observational Epidemiologic Research; 2009.

30. Byrt T: How good is that agreement? Epidemiology (Cambridge, Mass) 1996, 7(5):561.

31. Jurgens T, Whelan AM, MacDonald M, Lord L: Development and evaluation of an instrument for the critical appraisal of randomized controlled trials of natural products. BMC Complem Altern Med 2009, 9:11. doi:10.1186/1472-6882-9-11.

32. Gerber AJ, Kocsis JH, Milrod BL, Roose SP, Barber JP, Thase ME, Perkins P, Leon AC: A quality-based review of randomized controlled trials of psychodynamic psychotherapy. Am J Psychiatr 2011, 168(1):19-28.

33. Kocsis JH, Gerber AJ, Milrod B, Roose SP, Barber J, Thase ME, Perkins P, Leon $A C$ : A new scale for assessing the quality of randomized clinical trials of psychotherapy. Compr Psychiatr 2010, 51(3):319-324

34. Cipriani A, Malvini L, Furukawa TA, Barbui C: Relationship between quality of reports of antidepressant randomized controlled trials and treatment estimates: Systematic review, meta-analysis, and meta-regression analysis. J Clin Psychopharmacol 2007, 27(4):352-356.

35. Moncrieff J, Churchill R, Colin Drummond D, McGuire H: Development of a quality assessment instrument for trials of treatments for depression and neurosis. Int J Meth Psychiatr Res 2001, 10(3):126-133.

36. Boutron I, Ravaud P, Moher D, Tugwell P, Giraudeau B, Poiraudeau S, Nizard $\mathrm{R}$ : A checklist to evaluate a report of a nonpharmacological trial (CLEAR NPT) was developed using consensus. J Clin Epidemiol 2005 58(12):1233-1240.

37. Jadad AR, Moore RA, Carroll D, Jenkinson C, Reynolds DJM, Gavaghan DJ, McQuay HJ: Assessing the quality of reports of randomized clinical trials: Is blinding necessary? Control Clin Trials 1996, 17(1):1-12.

38. De Vet HCW, De Bie RA, Van Der Heijden GJMG, Verhagen AP, Sijpkes P, Knipschild PG: Systematic reviews on the basis of methodological criteria. Physiotherapy 1997, 83(6):284-289.

39. Verhagen AP, de Vet HC, de Bie RA, Kessels AG, Boers M, Bouter LM, Knipschild PG: The Delphi list: a criteria list for quality assessment of randomized clinical trials for conducting systematic reviews developed by Delphi consensus. J Clin Epidemiol 1998, 51(12):1235-1241.

40. Sherrington $C$, Herbert RD, Maher CG, Moseley AM: PEDro: A database of randomized trials and systematic reviews in physiotherapy. Man Ther 2000, 5(4):223-226.

41. Moseley AM, Herbert RD, Sherrington C, Maher CG: Evidence for physiotherapy practice: a survey of the Physiotherapy Evidence Database (PEDro). Aust J Physiother 2002, 48(1):43-49.

42. Van Tulder MW, Assendelft WJJ, Koes BW, Bouter LM, Bombardier C, Nachemson AL, Esmail R, Deyo RA, Shekelle PG, Bouter LM, et al: Method guidelines for systematic reviews in the Cochrane Collaboration Back Review Group for spinal disorders. Spine 1997, 22(20):2323-2330.

43. Van Tulder M, Furlan A, Bombardier C, Bouter L: Updated method guidelines for systematic reviews in the Cochrane Collaboration Back Review Group. Spine 2003, 28(12):1290-1299.

44. Bizzini $M$, Childs JD, Piva SR: Systematic review of the quality of randomized controlled trials for patellofemoral pain syndrome. J Orthop Sports Phys Ther 2003, 33(1):4-20.

45. Chalmers TC, Smith H Jr, Blackburn B: A method for assessing the quality of a randomized control trial. Control Clin Trials 1981, 2(1):31-49.

46. Reisch JS, Tyson JE, Mize SG: Aid to the evaluation of therapeutic studies. Pediatrics 1989, 84(5):815-827.
47. Andrew E: Method for assessment of the reporting standard of clinica trials with roentgen contrast media. Acta Radiologica - Series Diagnosis 1984, 25(1):55-58.

48. Imperiale TF, McCullough AJ: Do corticosteroids reduce mortality from alcoholic hepatitis? A meta-analysis of the randomized trials. Ann Intern Med 1990, 113(4):299-307.

49. Detsky AS, Naylor CD, O'Rourke K, McGeer AJ, L'Abbe KA: Incorporating variations in the quality of individual randomized trials into metaanalysis. J Clin Epidemiol 1992, 45(3):255-265.

50. Cho MK, Bero LA: Instruments for assessing the quality of drug studies published in the medical literature. JAMA 1994, 272(2):101-104.

51. Balas EA, Austin SM, Ewigman BG, Brown GD, Mitchell JA: Methods of randomized controlled clinical trials in health services research. Med Care 1995, 33(7):687-299.

52. Sindhu F, Carpenter L, Seers K: Development of a tool to rate the quality assessment of randomized controlled trials using a Delphi technique. J Adv Nurs 1997, 25(6):1262-1268.

53. Downs SH, Black N: The feasibility of creating a checklist for the assessment of the methodological quality both of randomised and non-randomised studies of health care interventions. J Epidemiol Commun Health 1998, 52(6):377-384.

54. Nguyen QV, Bezemer PD, Habets L, Prahl-Andersen B: A systematic review of the relationship between overjet size and traumatic dental injuries. Eur J Orthodont 1999, 21(5):503-515.

55. Smith LA, Oldman AD, McQuay HJ, Moore RA: Teasing apart quality and validity in systematic reviews: an example from acupuncture trials in chronic neck and back pain. Pain 2000, 86(1-2):119-132.

56. Arrive L, Renard R, Carrat F, Belkacem A, Dahan H, Le Hir P, Monnier-Cholley L, Tubiana JM: A scale of methodological quality for clinical studies of radiologic examinations. Radiology 2000, 217(1):69-74.

57. Huwiler-Muntener K, Juni P, Junker C, Egger M: Quality of reporting of randomized trials as a measure of methodologic quality. JAMA 2002, 287(21):2801-2804.

58. Yates SL, Morley S, Eccleston C, Williams ACDC: A scale for rating the quality of psychological trials for pain. Pain 2005, 117(3):314-325.

59. Graham N, Haines T, Goldsmith CH, Gross A, Burnie S, Shahzad U, Talovikova E: Reliability of three assessment tools used to evaluate randomized controlled trials for treatment of neck pain. Spine 2012, 37(6):515-522.

60. Hartling L, Bond K, Vandermeer B, Seida J, Dryden D, Rowe B: Applying the Risk of Bias tool in a systematic review of combination longacting betaagonists and inhaled corticosteroids for persistent asthma. PLoS Med 2011, 6(2):e17242.

61. Armijo-Olivo S, Stiles CR, Hagen NA, Biondo PD, Cummings GG: Assessment of study quality for systematic reviews: a comparison of the Cochrane Collaboration Risk of Bias Tool and the Effective Public Health Practice Project Quality Assessment Tool: methodological research. J Eval Clin Pract 2010:1-7.

62. Hartling L, Hamm MP, Milne A, Vandermeer B, Santaguida PL, Ansari M, Tsertsvadze A, Hempel S, Shekelle P, Dryden DM: Testing the Risk of Bias tool showed low reliability between individual reviewers and across consensus assessments of reviewer pairs. J Clin Epidemiol 2012. S0895-4356(12)00217-X. doi: 10.1016/j.jclinepi.2012.07.005.

63. Juni $P$, Witschi $A$, Bloch $R$, Egger $M$ : The hazards of scoring the quality of clinical trials for meta-analysis. JAMA 1999, 282(11):1054-1060.

64. Soares HP, Daniels S, Kumar A, Clarke M, Scott C, Swann S, Djulbegovic B: Bad reporting does not mean bad methods for randomised trials: Observational study of randomised controlled trials performed by the Radiation Therapy Oncology Group. BMJ 2004, 328(7430):22-24.

65. Sanderson S, Tatt ID, Higgins JPT: Tools for assessing quality and susceptibility to bias in observational studies in epidemiology: a systematic review and annotated bibliography. Int J Epidemiol 2007, 36(3):666-676.

doi:10.1186/1471-2288-13-116

Cite this article as: Armijo-Olivo et al:: Inconsistency in the items included in tools used in general health research and physical therapy to evaluate the methodological quality of randomized controlled trials: a descriptive analysis. BMC Medical Research Methodology 2013 13:116. 